\title{
Improvement in Heat Tolerance of Creeping Bentgrass with Melatonin, Rutin, and Silicon
}

\author{
Emily B. Merewitz ${ }^{1}$ and Sha Liu \\ Department of Plant, Soil, and Microbial Sciences, Michigan State University, 1066 Bogue Street, \\ East Lansing, MI 48824
}

\begin{abstract}
AdDitional InDEX wORDs. abiotic stress, Agrostis stolonifera, heat stress, turfgrass
Abstract. Naturally derived products that may enhance the functionality of fertilizers or other agricultural inputs are needed to reduce inputs associated with stress damage and increase the sustainability of turfgrass management. Damage to high-value creeping bentgrass (Agrostis stolonifera) turf areas caused by heat stress is a widespread problem. This study aimed to evaluate multiple, diverse treatments that may illicit antioxidant responses in plants, melatonin, rutin, and $\mathrm{Si}$, when applied as foliar pretreatments to heat stress. Creeping bentgrass plants were grown in growth chambers at optimal $\left(23^{\circ} \mathrm{C}\right)$ or heat stress conditions $\left(35^{\circ} \mathrm{C}\right)$. Turfgrass quality, chlorophyll content, leaf electrolyte leakage, photochemical efficiency, lipid peroxidation, antioxidant enzyme activity, and fatty acid content were measured to determine the effects of foliar treatments on heat stress responses. Melatonin, Si, and rutin were all found to improve some or all of the physiological parameters measured in the study, but only melatonin and Si reduced lipid peroxidation, increased antioxidant enzyme activity, and altered fatty acid contents. Melatonin- and Sitreated plants had greater superoxide dismutase and peroxidase activity and increased the content of the unsaturated fatty acid, linoleic acid, in creeping bentgrass leaves during heat stress compared with controls. Rutin improved turf quality and reduced electrolyte leakage during heat stress, but the mechanism associated with these changes is unclear because no changes were found in antioxidant enzyme activities or fatty acids. Melatonin and Si treatment promoted antioxidant enzyme activity and linoleic acid content of leaves, which have been associated with the improved heat tolerance of creeping bentgrass plants.
\end{abstract}

Creeping bentgrass is a cool-season turfgrass species grown on golf course putting greens, fairways, and tees and is prized for its functionality and overall durability (Turgeon, 2004). The species is sensitive to some abiotic and biotic stresses, which causes high input requirements when managing creeping bentgrass. Heat stress in summer months is a major problem for creeping bentgrass growing in temperate areas. There are many known physiological effects of heat stress on creeping bentgrass, including alternations in the rates of antioxidant enzyme activities (Xu and Huang, 2004). Various chemical treatments can influence the content and activity of endogenous antioxidants during a stress episode (Larkindale and Huang, 2005; Zhang and Schmidt, 2000). Oxidative stress and differential antioxidant system activity were two key factors that contributed to differences among cultivars of creeping bentgrass in heat tolerance (Liu and Huang, 2000).

In addition to the antioxidant system, the composition of lipids in plant membranes and the fatty acids that compose those lipids play an important role in plant tolerance of heat stress. Temperature and seasonal changes in light duration play a major role in regulating the saturation level of fatty acids in plants. It is generally accepted that plants increase the amount of unsaturated fatty acids to reduce rigidity of membranes during preparation for cold conditions and increase saturated fatty acids to reduce fluidity of plant membranes before the onset of high temperature conditions (Liu and Huang, 2000). However, the relationship of temperature to fatty acid

Received for publication 17 Jan. 2019. Accepted for publication 22 Feb. 2019. The authors thank the Michigan Turfgrass Foundation, AgBioResearch of Michigan State University, and the National Institute for Agriculture and Residex Co. for funding and support of this research.

${ }^{1}$ Corresponding author. E-mail: merewitz@msu.edu. composition shifts is not always entirely clear in all plant species and does not always affect the functionality of the given membrane, such as in photosynthetic membranes (McCourt et al., 1987). Saturated fatty acids commonly increase in response to heat stress in cyanobacteria and in multiple organelles of various plant species (Nishiyama et al., 1999; Vigh et al., 1989; Whitaker et al., 1997). In creeping bentgrass, extracts of leaf tissue for the more heat-tolerant 'L-93' compared with the less heat-tolerant 'Penncross' contained a higher proportion of saturated lipids before heat stress than 'Penncross' (Larkindale and Huang, 2004). It is possible that exogenous treatments to creeping bentgrass that may enhance saturated fatty acid content could improve heat stress tolerance.

Compared with the large amount of research done on different compounds that could promote plant heat tolerance, few chemical treatments have made a major impact on the turfgrass product market for boosting plant tolerance of heat stress. Products that are available to alleviate summer stress issues are primarily pesticides that inhibit biotic diseases common during summer months on putting greens. The turfgrass industry desires new possibilities for chemical treatment options that reduce the need for pesticide inputs to increase the sustainability of turfgrass practices.

One possibility is melatonin, which when found in plants is known as phytomelatonin ( $\mathrm{N}$-acetyl-5-methoxytryptamine). Melatonin increases in response to heat stress in some plant species. The function of melatonin in plants has not been fully elucidated, but it is thought to play a role in heat tolerance (Nawaz et al., 2016). In human biological studies, melatonin was found to regulate numerous physiological functions and behaviors (Arnao and Hernandez-Ruiz, 2015). The mechanism of action of melatonin in plants during heat stress may be 
related to its induction of plant antioxidants and protection of proteins against degradation, denaturation, and/or aggregation (Arnao and Hernandez-Ruiz, 2015). Foliar treatment with melatonin reduced electrolyte leakage in tomato [Solanum lycopersicum (Xu et al., 2016)]. Stress responses after melatonin treatment have yet to be investigated for cool-season turfgrass species.

Rutin, a phenolic compound (quercetin-3-rhamnosyl glucoside) prevalent in plants such as asparagus [Asparagus acutifolius (Wang et al., 2003)] in the flavonoid family, has antioxidant properties and has been shown to reduce lipid peroxidation in vitro (Yang et al., 2008). Compared with other antioxidant compounds, relatively little research has been done to determine the effects of rutin on plants under stress. In quinoa (Chenopodium quinoa) plants, high levels of rutin were expressed during salinity stress, and broad bean (Vicia faba) plants treated with rutin showed reduced symptoms associated with salinity stress (Ismail et al., 2015). Animal biology research indicates that dosing of exogenous antioxidants is important, and excess of certain compounds can have prooxidative activity and cause cytotoxicity (Bouayed and Bohn, 2010). Also, certain degrees of accumulation of reactive oxidative species (ROS) are important for functional stress signaling and subsequent tolerance (Miller et al., 2008). Therefore, testing of exogenous antioxidants is an important part of developing potential beneficial compounds to include in products for the turfgrass industry and for other agricultural crops. To our knowledge, whether exogenous rutin has utility in protection from other abiotic stresses or specifically in turfgrass species has yet to be determined.

Of the three chemicals exerting antioxidant responses in plants evaluated here, $\mathrm{Si}$ is the most studied in turfgrass species and related grasses for promoting abiotic stress tolerance. For instance, it has been shown to reduce oxidative stress of wheat [Triticum aestivum (Gong et al., 2005)] during drought, salt stress of barley [Hordeum vulgare (Liang et al., 2003)], wear stress and disease tolerance of st. augustinegrass (Stenotaphrum secundatum) and other turfgrass species (Datnoff, 2005). How plant-available Si may exert antioxidant effects is not entirely clear, but it has been shown to improve metabolic health under stress, most likely by stabilizing plant membranes and inducing antioxidant enzyme responses in plants (Kim et al., 2017). For instance, $\mathrm{SiO}_{2}$ has been shown to decrease the transpiration rate and membrane permeability of rice (Oryza sativa) grown in hydroponics and exposed to polyethylene glycol-induced drought stress (Agari et al., 1998). Sodium silicate, applied as a soil amendment, increased antioxidant enzyme activity and net $\mathrm{CO}_{2}$ fixation in wheat plants under drought stress (Gong et al., 2005). More studies on the effects of $\mathrm{Si}$ are needed to determine its usefulness to the turfgrasss industry, particularly compared with other antioxidant-inducing compounds and for heat stress tolerance.

Because melatonin, $\mathrm{Si}$, and rutin are diverse in structure and have all been described as causing pleiotropic antioxidant responses in plants, we aimed to test whether these compounds improve creeping bentgrass heat tolerance and whether they influence antioxidant systems, lipid peroxidation levels, and fatty acid composition during heat stress. We hypothesized that antioxidant-inducing stress defense treatments of plants could allow for plants to modulate fatty acid changes associated with heat tolerance better than control plants due to less stress damage.

\section{Materials and Methods}

Plant material and Growth Conditions. Sod plugs of creeping bentgrass 'Penncross' were harvested from the Hancock Turfgrass Research Center in East Lansing, MI, in May 2017. The sod pieces were potted in PVC tubes $(10.2 \mathrm{~cm}$ diameter and $20 \mathrm{~cm}$ length) filled with sterilized soil (a sandy loam, Typic Hapludult soil). All plants were allowed to become established for $30 \mathrm{~d}$ in the greenhouse with daily irrigation. All plants were trimmed at $\approx 3.81 \mathrm{~cm}$ to maintain a uniform leaf canopy. Plants were fertilized with Hoagland's solution twice per week throughout the establishment (Hoagland and Arnon, 1950). Plants were then moved into a growth chamber (TPR series; Biochambers, Winnipeg, Canada) and were given $15 \mathrm{~d}$ to acclimate to growth chamber conditions before treatments were imposed. The optimal growth chamber conditions were set to a relative humidity average of $65 \%$, daily temperature of $23 / 20{ }^{\circ} \mathrm{C}$ day/night, and $700 \mu \mathrm{mol} \cdot \mathrm{m}^{-2} \cdot \mathrm{s}^{-1}$ light intensity for $14 \mathrm{~h}$.

EXPERIMENTAL TREATMENTS. A total of 40 plants, each consisting of a sod piece within one individual container, were used in the experiment. At $14 \mathrm{~d}$ before any temperature treatment, all plants were exposed to different chemical treatments. Chemical treatments included 1) $100 \mu \mathrm{M} \cdot \mathrm{L}^{-1}$ melatonin, 2) $200 \mu \mathrm{M} \cdot \mathrm{L}^{-1}$ melatonin, 3) $2 \mathrm{mM}$ rutin, 4) $4 \mathrm{~mm}$ rutin, and 5) $0.73 \mathrm{~L} \cdot \mathrm{ha}^{-1}$ monosilicic acid $\left(\mathrm{H}_{4} \mathrm{SiO}_{4}\right)$. The rates for melatonin were selected on the basis of previous literature on various species (Erland et al., 2015). The rates for rutin were selected on the basis of methods in Yang et al. (2016). Deionized water was used as control. Chemical treatments were applied three times daily to four replicate plants for $2 \mathrm{~d}$, by spraying $50 \mathrm{~mL}$ of the appropriate solution on the foliage of the plant. The first chemical treatments were applied $14 \mathrm{~d}$ before the temperature treatments, and the second was applied on day 0 of heat treatment. For temperature treatment, 20 plants were transferred to the high temperature growth chamber and 20 were kept at optimal conditions. The growth chamber conditions for heat stress were set to a relative humidity average of $65 \%$, daily temperature of $35 / 25{ }^{\circ} \mathrm{C}$ day/night, and 700 $\mu \mathrm{mol} \cdot \mathrm{m}^{-2} \cdot \mathrm{s}^{-1}$ light intensity for $14 \mathrm{~h}$. For the 2017 study, chemical treatments and heat stress were initiated on 13 July. For the 2018 study, chemical treatment and heat stress began on 2 Feb. The heat treatment lasted for $49 \mathrm{~d}$ for both the 2017 and 2018 experiments, which corresponded to 7 Sept. 2017 and 23 Mar. 2018.

Physiological evaluation. Turf quality (TQ) was used to visually rate turf plants based on color, density, and uniformity of the grass using a scale of 1 to $9(9=$ fully turgid, dense green canopy, 1 = completely dead plants) (Beard, 1973). Plant leaf chlorophyll content (CHL) was quantified using a dimethyl sulfoxide (DMSO) extraction method in a spectrophotometer (Genesys10s ultraviolet-Vis; Thermo Fisher Scientific, Waltham, MA) based on absorption at 663 and $645 \mathrm{~nm}$ of the extraction solution after soaking $\approx 10$ leaves in DMSO overnight in the dark (Arnon, 1949). The extraction solution was strained from leaves for all samples, and the leaves were kept in an oven until determination of dry weights. Leaf electrolyte leakage (EL) was determined by measuring the ratio of live to dead leaf electrolyte conductivity $\left(\mathrm{C}_{\mathrm{i}} / \mathrm{C}_{\mathrm{d}} \times 100\right)$ using a conductivity meter (model 3200; YSI, Yellow Springs, OH) where $C_{i}$ was the live leaf electrolyte conductivity and $C_{d}$ was the dead electrolyte conductivity (Blum and Ebercon, 1981). 
Photochemical efficiency $\left(F_{\mathrm{v}} / F_{\mathrm{m}}\right)$ was evaluated by measuring the ratio of variable to maximum photo yield $\left(F_{\mathrm{v}} / F_{\mathrm{m}}\right)$. After being adapted to $30 \mathrm{~min}$ of darkness, the $F_{\mathrm{v}} / F_{\mathrm{m}}$ ratio of leaf samples was monitored by using a chlorophyll fluorescence meter (Fim 1500; Dynamax, Houston, TX).

For antioxidant activity assays and measurement of lipid, peroxidation methods were taken from Dhindsa et al. (1981), Heath and Packer (1968), and Chance and Maehly (1955) with minor modifications. Approximately $0.25 \mathrm{~g}$ of fresh leaf tissues was frozen immediately in liquid nitrogen and then stored at $-80{ }^{\circ} \mathrm{C}$ until use. Frozen leaves were homogenized with $4 \mathrm{~mL}$ cold extraction solution (150 mM phosphate buffer, $\mathrm{pH}=7.0$ ). The homogenate was centrifuged at $10,000 \mathrm{~g}_{\mathrm{n}}$ for $20 \mathrm{~min}$ at $4{ }^{\circ} \mathrm{C}$. The supernatant was used to measure the activity of superoxide dismutase (SOD), catalase (CAT), peroxidase (POD), ascorbate peroxidase (APX), and the level of lipid peroxidation. For SOD analysis, the reaction solution $(3 \mathrm{~mL})$

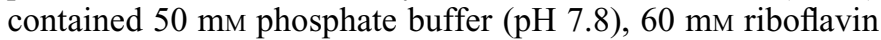
(7,8-dimethyl-10-ribitylisoalloxazine), $195 \mathrm{~mm}$ methionine [2amino-4-(methyl-thio)-butyric acid], $3 \mathrm{~mm}$ ethylenediaminetetraacetic acid (EDTA), $1.125 \mathrm{~mm}$ nitro blue tetrazolium (NBT [2,2-di-p-nitrophenyl-5,5-diphenyl-(3,3-dimethoxy-4,4diphenylene) ditetrazolium chloride] $\}$, and $100 \mathrm{~mL}$ of extracted enzyme solution. A solution containing no enzyme solution was used as the control. The absorbance of each solution was measured at $560 \mathrm{~nm}$ using a spectrophotometer, and one unit of enzyme activity was defined as the amount of enzyme that would inhibit $50 \%$ of NBT photoreduction. For POD analysis, the $3-\mathrm{mL}$ reaction mixture contained $1.85 \mathrm{~mL}$ of a $0.1 \mathrm{M}$ acetic acid-sodium acetate buffer $(\mathrm{pH} 5.0), 1 \mathrm{~mL} \mathrm{50 \%}$ guaiacol solution, and $50 \mathrm{~mL}$ of the extracted enzymes. The reaction was started with $100 \mathrm{~mL}$ of $0.75 \%$ hydrogen peroxide $\left(\mathrm{H}_{2} \mathrm{O}_{2}\right)$ solution. Spectrophotometer readings were recorded at $460 \mathrm{~nm}$ once every $1 \mathrm{~min}$ within the first $3 \mathrm{~min}$. One unit of POD activity was defined as the absorbance change of one unit per minute. The activity of CAT was determined based on the oxidation of $\mathrm{H}_{2} \mathrm{O}_{2}$. The reaction solution $(3 \mathrm{~mL})$ contained $50 \mathrm{~mm}$ phosphate buffer ( $\mathrm{pH} 7.0$ ), $45 \mathrm{~mm} \mathrm{H}_{2} \mathrm{O}_{2}$, and $100 \mathrm{~mL}$ of extracted solution. The reaction was initiated by adding the enzyme solution. Changes in absorbance at $240 \mathrm{~nm}$ were recorded every $10 \mathrm{~s}$ for $60 \mathrm{~s}$ using a spectrophotometer. One unit of CAT activity was defined as the absorbance change of 0.01 unit per minute (Chance and Maehly, 1955). For APX analysis, the reaction solution $(3 \mathrm{~mL})$ contained $100 \mathrm{~mm}$ sodium acetate buffer ( $\mathrm{pH}$ 5.8), $3 \mathrm{~mm}$ EDTA, $5 \mathrm{~mm} \mathrm{H}_{2} \mathrm{O}_{2}$, and $100 \mathrm{~mL}$ of extracted solution. The reaction was initiated by adding the enzyme extract. Changes in absorbance at $290 \mathrm{~nm}$ were read every $10 \mathrm{~s}$ for $60 \mathrm{~s}$ using a spectrophotometer. One unit of APX activity was defined as an absorbance change of 0.01 per min (Nakano and Assada, 1981).

The level of lipid peroxidation was determined by measuring malondialdehyde (MDA) content (Dhindsa et al., 1981). Enzyme extraction ( $1 \mathrm{~mL})$ was added to $2 \mathrm{~mL}$ of a reaction solution containing $20 \%(\mathrm{v} / \mathrm{v})$ trichloroacetic acid and $0.5 \%(\mathrm{v} / \mathrm{v})$ thiobarbituric acid. The solution was placed in a water bath at $95^{\circ} \mathrm{C}$ for $30 \mathrm{~min}$ and then quickly cooled in an ice-water bath. After the solution was centrifuged for $10 \mathrm{~min}$, the absorbance of the supernatant was read at 532 and $600 \mathrm{~nm}$. Absorbance at $600 \mathrm{~nm}$ was subtracted from that at $532 \mathrm{~nm}$, and MDA content was calculated using this adjusted absorbance and the extinction coefficient of $155 \mathrm{~mm}^{-1} \cdot \mathrm{cm}^{-1}$ (Heath and Packer, 1968).
Fatty acid extraction was performed with $\approx 200 \mathrm{mg}$ leaf samples at $0,14,28$, and $42 \mathrm{~d}$ after temperature treatment according to the method of Cyril et al. (2002) with modifications. Preheated $3 \mathrm{~mL}$ of isopropanol $\left(75^{\circ} \mathrm{C}\right)$ with $0.01 \%$ butylated hydroxytoluene (BHT) was added in test tubes with frozen leaf material. After the samples were heated in the water bath for $15 \mathrm{~min}, 0.6 \mathrm{~mL}$ distilled water and $1.5 \mathrm{~mL}$ chloroform were added. All test tubes with samples were placed on the shaker at room temperature $\left(23^{\circ} \mathrm{C}\right)$ for $5 \mathrm{~h}$, and the lipids in the lower layer were transferred into new test tubes. An additional 4 $\mathrm{mL}$ of chloroform/methanol (2:1) with $0.01 \%$ BHT was added to leaf material and extracted as described earlier. Extractions were combined, and $1 \mathrm{~mL}$ of potassium chloride was added. After centrifugation at $5000 \mathrm{~g}_{\mathrm{n}}$ for $10 \mathrm{~min}$, the top layer of the extraction was removed. Distilled water $(2 \mathrm{~mL})$ was added to the test tubes with the extraction solution, which were then centrifuged for an additional $10 \mathrm{~min}$ at $5000 \mathrm{~g}_{\mathrm{n}}$. After the top layer was removed, the remaining sample was evaporated using a vacuum centrifugation. Remaining leaf material was dried in an oven to determine the dry weight. The fatty acid analysis was performed at the Mass Spectrometry and Metabolomics Core at Michigan State University using a mass selective detector (5975 inert XL MSD; Agilent Technologies, Santa Clara, CA). A column (VF-5ms, $30 \mathrm{~m} \times 0.25 \mathrm{~mm} \times 0.25 \mu \mathrm{m}$; Agilent Technologies) was used for separation and quantification of fatty acids. The temperature profile was set to $30{ }^{\circ} \mathrm{C}$ for $4 \mathrm{~min}$, $10{ }^{\circ} \mathrm{C} \cdot \mathrm{min}^{-1}$ to $320^{\circ} \mathrm{C}$ and $320^{\circ} \mathrm{C}$ for $2 \mathrm{~min}$. As a measure of fatty acid unsaturation, double bond indexes (DBIs) were calculated as described in Cyril et al. (2002).

EXPERIMENTAL DESign AND STATISTICAL ANALYSis. The growth chamber experiments were conducted as completely randomized block designs with temperature treatment as the main block and chemical treatment randomized within the block. The experiment was repeated using the same growth chambers. All data were subjected to analysis of variance according to the mixed procedure using SAS software (version 9.4; SAS Institute; Cary, NC). Due to lack of statistical interaction, data from repeated experiments were pooled together. Differences between treatment means were separated by Fisher's protected least significance difference test $(P \leq 0.05)$.

\section{Results}

Plants under optimal temperature conditions maintained unchanged levels of TQ, CHL, EL, and $F_{v} / F_{m}$ throughout the duration of the study, and no significant differences in these parameters occurred due to chemical treatments without stress conditions (data not shown). TQ was decreased due to heat treatment (Fig. 1A). Heat-stressed plants treated with melatonin 200 , rutin 4 and Si had significantly higher TQ than control plants after $28 \mathrm{~d}$ of heat treatment. Under the heat condition, plants treated with $\mathrm{Si}$ and melatonin 200 showed significantly higher TQ than plants treated with rutin 2, melatonin 100, and controls on days 35 and 42 (Fig. 1A). CHL declined markedly throughout the high-temperature treatment period. Plants treated with Si and melatonin 200 showed significantly higher CHL than control plants after $28 \mathrm{~d}$ of heat treatment (Fig. 1B). Heatstressed plants treated with rutin 4 showed markedly higher CHL than control plants at days 42 and 49. EL was increased due to heat treatment (Fig. 1C). Significantly lower EL was shown in plants treated with Si and melatonin 200 than control 

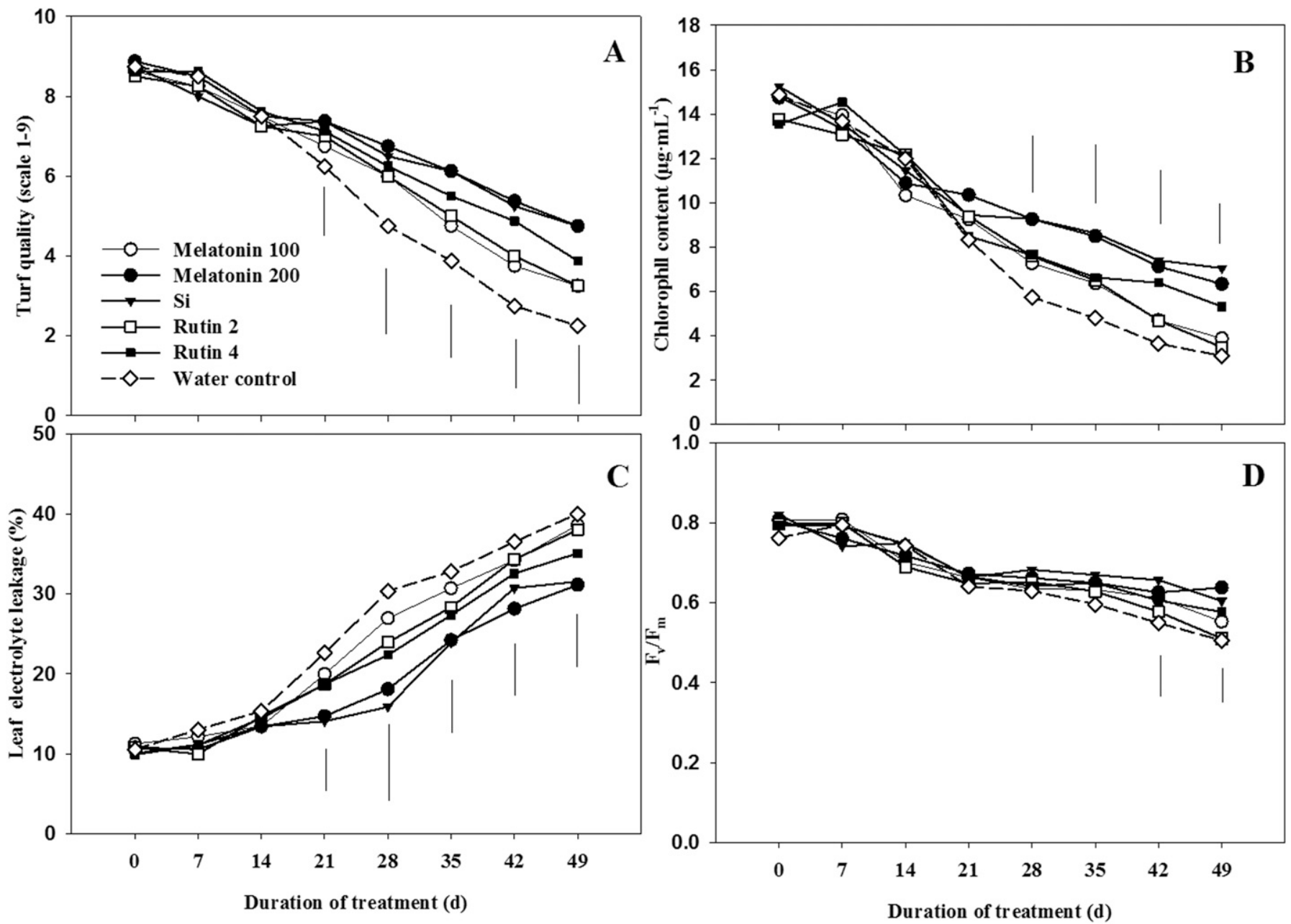

Fig. 1. (A) Turf quality ratings $\left(1=\right.$ necrotic, $9=$ healthy), $(\mathbf{B})$ leaf electrolyte leakage, $(\mathbf{C})$ leaf chlorophyll content, and (D) photochemical efficiency $\left(\mathrm{F}_{\mathrm{v}} / \mathrm{F}_{\mathrm{m}}\right)$ of creeping bentgrass plants growing in a growth chamber exposed to exogenous foliar treatments and high temperature stress $\left(35^{\circ} \mathrm{C}\right)$. The treatment rates were 100 and $200 \mu \mathrm{m} \cdot \mathrm{L}^{-1}$ of melatonin and 2 and $4 \mathrm{~mm}$ of rutin. Least significant difference bars are shown on days when significant differences among chemical treatments were detected $(P \leq 0.05)$.

plants after $21 \mathrm{~d}$ of heat stress. Under heat conditions, plants treated with melatonin 200 showed significantly lower EL than plants treated with rutin 2 , melatonin 100 , and water controls on days 21,42 , and 49 (Fig. 1 C). $F_{\mathrm{v}} / F_{\mathrm{m}}$ of heat-treated plants declined markedly throughout the study (Fig. 1D). Heatstressed plants treated with $\mathrm{Si}$ showed significantly higher $F_{\mathrm{v}}$ $/ F_{\mathrm{m}}$ than control plants on days 42 and 49 . Heat-stressed plants treated with melatonin 200 showed significantly higher $F_{\mathrm{v}} / F_{\mathrm{m}}$ than control plants on day 49 (Fig. 1D).

Plants growing in optimal temperatures had no change in MDA content or antioxidant activities (data not shown). All plants exposed to high temperatures had a significant increase in MDA content, starting at day 14 of treatment and subsequently increasing through $49 \mathrm{~d}$ of heat treatment (Fig. 2A). A decline in antioxidant enzyme activities over time was observed (Fig. 2B-E). Treatment with exogenous antioxidants had a significant effect on MDA levels during heat stress. On days 35 and 49, significantly lower MDA content was detected for melatonin 200- and Si-treated plants (Fig. 2A). The same treatments induced an increase in SOD and POD activity on several dates (e.g., on days 28, 35, and 49 of treatment) compared with controls. Less significant differences among chemical treatments were detected for APX and CAT. Only on days 21 and 49 of heat were there any significant differences among chemical treatments for APX and CAT, respectively.

For unsaturated fatty acids, no statistically significant differences due to temperature or chemical treatment were detected for 18:1 and 18:3 (data not shown). Temperature had a significant effect on the accumulation of unsaturated fatty acids 18:2 and $18: 3$, as they decreased in content by day 42 of heat compared with $0 \mathrm{~d}$. Chemical treatments had the most marked effect on unsaturated fatty acid 18:2 content: on 3 sampling days, significant differences between chemical treatments were observed for 18:2 (Table 1). For instance, melatonin 200 and Si treatments had higher 18:2 content on most days during heat stress and $1 \mathrm{~d}$ in control conditions compared with the watered control plants. Differences among chemical treatments for saturated fatty acids were less clear, as only on a few days were significant differences detected between treatments and some of those differences also occurred under optimal temperature conditions. High temperature caused a general reduction in the DBI averaged over all treatments on days 28 and 42 of the study, but to a lesser extent in Si-treated plants (Fig. 3). Si-treated plant DBI remained similar to the control levels at day 42 of sampling in the heat-treated plants, whereas the watered controls and other treatments had DBIs that were significantly lower than the Si-treated plants. 

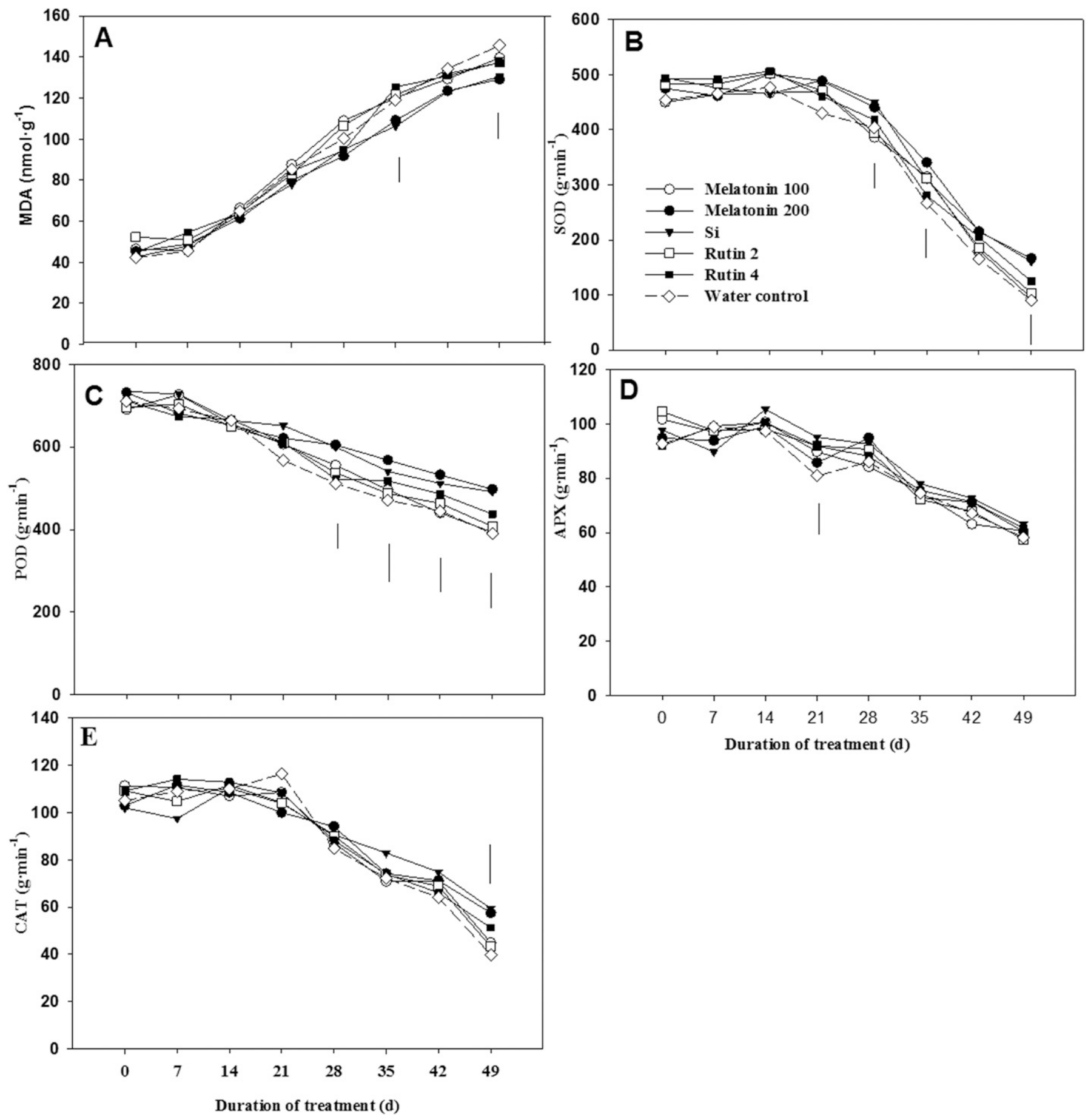

Fig. 2. Lipid peroxidation levels measured as (A) malondialdehyde content (MDA) and antioxidant enzyme activity of (B) superoxide dismutase (SOD), (C) peroxidase (POD), (D) ascorbate peroxidase (APX), and (E) catalase (CAT) from leaf extracts of creeping bentgrass plants exposed to $35^{\circ} \mathrm{C}$ and various exogenous foliar treatments. All units are based on dry weights of leaf tissues. The treatment rates were 100 and $200 \mu \mathrm{m} \cdot \mathrm{L}^{-1}$ of melatonin and 2 and $4 \mathrm{~mm}$ of rutin. Least significant difference bars are shown on days where significant differences among chemical treatments were detected $(P \leq 0.05)$.

\section{Discussion}

Use of naturally derived plant priming agents to promote plant stress tolerance may be a viable method to conserve natural resources and reduce the use of pesticides in the turfgrass industry. Here, we explored the use of the natural antioxidant compounds melatonin, rutin, and Si on creeping bentgrass responses to heat stress.
Melatonin has been found to play a role in various responses to abiotic stress in various plant species. Here we found that the higher rate of melatonin $\left(200 \mu \mathrm{M} \cdot \mathrm{L}^{-1}\right)$ had primarily a significant effect on the antioxidant activity of SOD and POD. No major differences were found for APX and CAT in response to melatonin treatment and heat stress. Liang et al. (2018) found reduced $\mathrm{H}_{2} \mathrm{O}_{2}$ content in melatonin treated kiwifruit (Actinidia deliciosa) seedlings and greater activity of many of the 

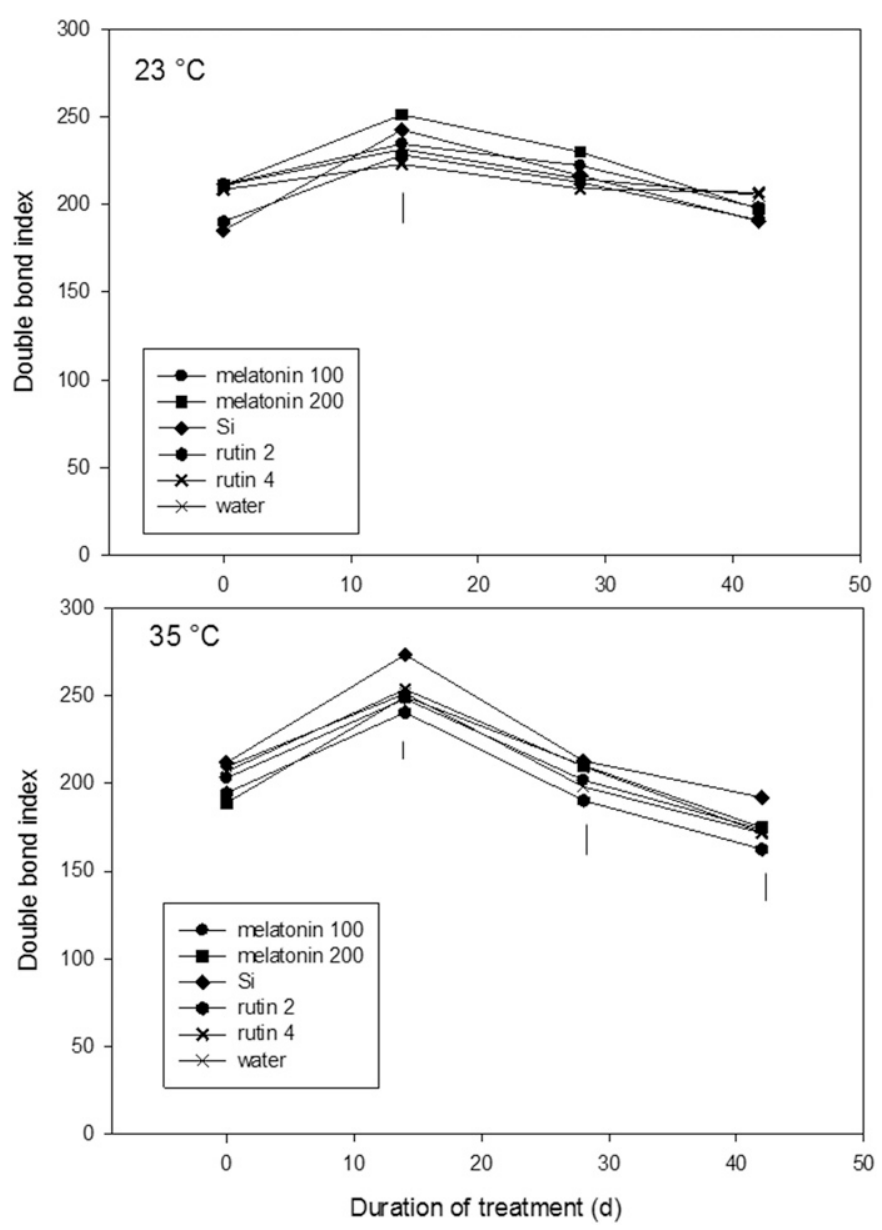

Fig. 3. Double bond index (DBI) at $(\mathbf{A})$ optimal $\left(23^{\circ} \mathrm{C}\right)$ and $(\mathbf{B})$ heat stress $\left(35^{\circ} \mathrm{C}\right)$ conditions for fatty acids of creeping bentgrass treated with foliar applications of a given antioxidant chemical treatment. The treatment rates were 100 and $200 \mu \mathrm{m} \cdot \mathrm{L}^{-1}$ of melatonin and 2 and $4 \mathrm{~mm}$ of rutin. Least significant difference bars are shown on days when significant differences among chemical treatments in DBI were detected $(P \leq 0.05)$.

antioxidant enzymes such as SOD, CAT, POD, and APX. Differences in antioxidant enzyme responses to melatonin treatment in our results compared with the results of Liang et al. (2018) could be due to the different species used for the studies and the differences in plant maturity (mature plant vs. seedlings). Treatments that were associated with improved antioxidant content also influenced fatty acid content in leaf tissues. The high rate of melatonin and Si treatments had higher linoleic acid (18:2) content on several days during heat stress. This observation could be related to the treatments causing a reduction in damage to linoleic acid associated with heat stress, possibly linoleic acid oxidation. Linoleic acid, which is readily oxidized under certain conditions, is used as a substrate within in vitro assays to determine the antioxidant activity of various compounds, such as phenolics (Farag et al., 1989). Linoleic acid is known to increase in various creeping bentgrass cultivars due to heat stress (Larkindale and Huang, 2004). Further research would be needed to determine whether melatonin or Si played a role in a plant's ability to protect linoleic acid from oxidation.

Other heat stress tolerance mechanisms could also have played a role in the improved heat tolerance of creeping bentgrass in response to melatonin treatment. In bermudagrass, endogenous melatonin increased markedly in response to low potassium stress as quickly as $12 \mathrm{~h}$ after $\mathrm{K}$ limitation. Exogenous melatonin boosted $\mathrm{K}$ content in plants under low $\mathrm{K}$ treatment compared with controls (Chen et al., 2017). Potassium ions are well known to be involved in regulating plant tolerance of multiple abiotic stresses due to their involvement in stomatal closure, osmotic adjustment, and other functions. Additional mechanisms could be related to heat-protective responses. Both endogenous and exogenous melatonin were found to promote the expression of heat shock factors in Arabidopsis thaliana (Shi et al., 2015), and exogenous application in tomato plants also enhanced certain heat shock proteins (Xu et al., 2016). Thus, further research could be performed to determine whether other protective mechanisms may have played a role in the melatonin-induced promotion of heat tolerance found here for creeping bentgrass.

Si has been shown to accumulate in cell walls to maintain stability of those cells under stress conditions and reduce EL, particularly in epidermal cells of rice plants, which provided protection from drought and improved performance during heat stress (Agari et al., 1998). More recently, a meta-analysis of 145 experiments was performed to document the effects of $\mathrm{Si}$ on plant abiotic stress tolerance (Cooke and Leishman, 2016). This analysis confirmed that across a broad range of plant species, $\mathrm{Si}$ can effectively alleviate oxidative damage but was not always consistent in the effects on antioxidants within plant leaves. The study concluded that Si may be a beneficial component of fertilizers, but more studies are needed to confirm these findings under natural conditions or in field settings. Thus, testing of Si on turfgrass species in the field for abiotic and biotic stress responses would be a useful next step to help move $\mathrm{Si}$ into more products in the turfgrass industry. Sand is silicon dioxide, which causes $\mathrm{Si}$ to be the second most abundant element in the earth's crust, and thus the utility of Si fertilizers in the turfgrass industry could be location- and species-specific. Some turfgrasses, such as putting greens species (e.g., creeping bentgrass), are grown in sand or are top-dressed with sand and are likely exposed to a significant amount of Si already (although it may not be plant available for absorption). Regardless, Si fertilizer under controlled conditions seems to have a positive effect on heat stress tolerance of creeping bentgrass.

Rutin improved creeping bentgrass responses to heat stress via enhanced TQ and CHL but did not have a major effect on lipid peroxidation or antioxidant enzyme activities or fatty acid composition of leaf tissues. Similar results were found by Singh et al. (2017), as the total antioxidant capacity of rice plants treated with rutin were not significantly different from control plants but the ROS levels were lower in rutin-treated plants. Rutin is thought to interact with phospholipids at the lipidwater interface and reduce oxidative stress of lipids (Agati et al., 2013). Perhaps the application rate or other factors prevented rutin from influencing lipid responses in our study. Additional research is needed to determine what mechanism may have played a role in the enhanced performance of creeping bentgrass during heat after rutin treatment. Rutin has also been evaluated for use as a priming agent against bacterial pathogens (Farahani and Taghavi, 2018; Yang et al., 2016). More research is needed on the role of rutin in abiotic stress protection of plants. 
Table 1. Effects of temperature and chemical treatment on saturated (16:0, palmitic acid; 18:0, stearic acid) and unsaturated fatty acid (16:1, palmitoleic acid; 18:2, linoleic acid) contents of leaf tissue of creeping bentgrass plants growing in a growth chamber. The treatment rates were 100 and $200 \mu \mathrm{M} \cdot \mathrm{L}^{-1}$ of melatonin and 2 and $4 \mathrm{mM}$ of rutin.

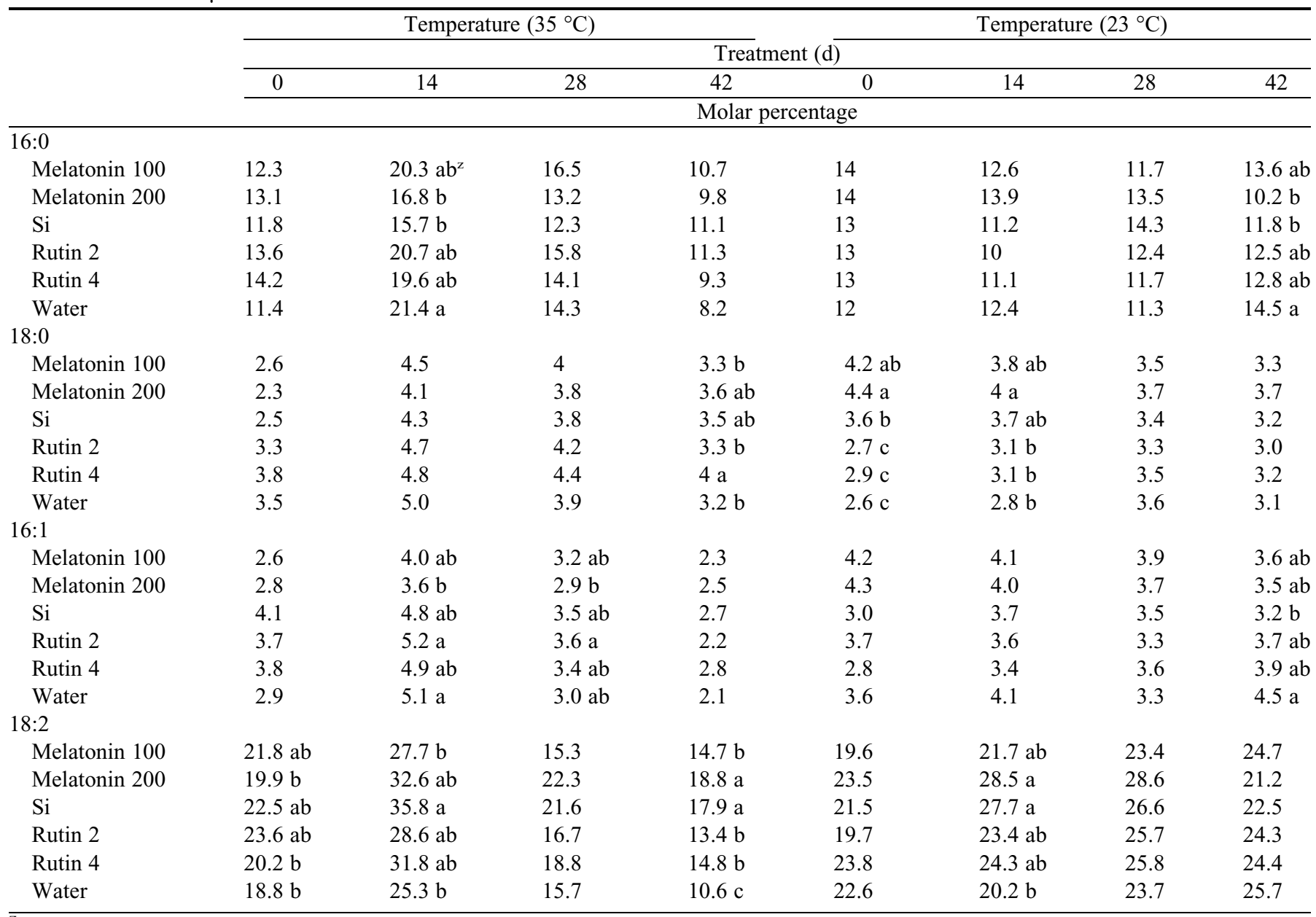

${ }^{\bar{z}}$ Different letters indicate significant differences among treatments, and no letter indicates that no significant differences were detected via Fisher's protected least significant difference test at $P \leq 0.05$.

Melatonin, $\mathrm{Si}$, and rutin were all found to improve some or all of the physiological parameters studied, including TQ, CHL, $\mathrm{F}_{\mathrm{v}} / \mathrm{F}_{\mathrm{m}}$, and reduced EL. Only melatonin and Si reduced lipid peroxidation, increased antioxidant enzyme activity, and altered fatty acid contents. Melatonin- and Si-treated plants had greater SOD and POD activity and increased the content of the unsaturated fatty acid linoleic acid in creeping bentgrass leaves during heat stress compared with controls. Rutin improved TQ and reduced EL during heat stress, but the mechanism associated with these changes is unclear because no changes were found in antioxidant enzyme activities or fatty acids. These three treatments may be useful in the turfgrass industry to promote heat tolerance of creeping bentgrass. Field testing and testing these treatments on other turfgrass species in response to various abiotic and biotic stresses may be warranted.

\section{Literature Cited}

Agari, S., N. Hanaoka, O. Ueno, A. Miyazaki, F. Kubota, W. Agata, and P.B. Kaufman. 1998. Effects of silicon on tolerance to water deficit and heat stress in rice plants (Oryza sativa L.), monitored by electrolyte leakage. Plant Prod. Sci. 2:96-103.

Agati, G., C. Brunetti, M. Ferdinando, F. Ferrini, S. Pollastri, and M. Tattini. 2013. Functional roles of flavonoids in photoprotection: New evidence, lessons from the past. Plant Physiol. Biochem. 72:35-45.
Arnao, M. and J. Hernandez-Ruiz. 2015. Functions of melatonin in plants: A review. J. Pineal Res. 59:133-150.

Arnon, D.I. 1949. Copper enzymes in isolated chloroplasts. Polyphenoloxidase in Beta vulgaris. Plant Physiol. 24:1-15.

Beard, J.B. 1973. Turfgrass: Science and culture. Prentice Hall, Englewoods Cliffs, NJ.

Blum, A. and A. Ebercon. 1981. Cell membrane stability as a measure of drought and heat tolerance in wheat. Crop Sci. 21:43-47.

Bouayed, J. and T. Bohn. 2010. Exogenous antioxidants-doubleedged swords in cellular redox state. Oxid. Med. Cell. Longev. 3:228-237.

Chance, B. and A.C. Maehly. 1955. Assay of CAT and POD. Methods Enzymol. 2:764-775.

Chen, L., J. Fan, Z. Hu, X. Huang, E. Amombo, A. Liu, A. Bi, K. Chen, Y. Xie, and J. Fu. 2017. Melatonin is involved in regulation of bermudagrass growth and development and response to low $\mathrm{k}+$ stress. Front. Plant Sci. 8:2038.

Cooke, J. and M.R. Leishman. 2016. The functional role of silicon in plant biology: Consistent alleviation of abiotic stress with silicon addition: A meta-analysis. Funct. Ecol. 30:1340-1357.

Cyril, J., G.L. Powell, R.R. Duncan, and W.V. Baird. 2002. Changes in membrane polar lipid fatty acids of seashore paspalum in response to low temperature exposure. Crop Sci. 42:2031-2037.

Datnoff, L.E. 2005. Silicon in the life and performance of turfgrass. Appl. Turfgrass Sci., doi: 10.1094/ATS-2005-0914-01-RV. 
Dhindsa, R.S., P.P. Dhindsa, and T.A. Thorpe. 1981. Leaf senescence: Correlation with increased levels of membrane permeability and lipid peroxidation, and decreased levels of SOD and CAT. J. Expt. Bot. 32:93-101.

Erland, L.A.E., S.J. Murch, R.J. Reiter, and P.K. Saxena. 2015. A new balancing act: The many roles of melatonin and serotonin in plant growth and development. Plant Signal. Behav. 10(11):e1096469.

Farag, R.S., A.Z.M.A. Badei, F.M. Hewedi, and G.S.A. El-Baroty. 1989. Antioxidant activity of some spice essential oils on linoleic acid oxidation in aqueous media. J. Amer. Oil Chem. 66:792-799.

Gong, H., X. Zhu, K. Chen, S. Wang, and C. Zhang. 2005. Silicon alleviates oxidative damage of wheat plants in pots under drought. Plant Sci. 169:313-321.

Heath, R.L. and L. Packer. 1968. Photoperoxidation in isolated chloroplasts. Arch. Biochem. Biophys. 125:189-198.

Hoagland, D.R. and D.I. Arnon. 1950. The water-culture method for growing plants without soil. California Agr. Expt. Sta. Circ. 347.

Kim, Y.H., A.L. Khan, M. Waga, and I.J. Lee. 2017. Silicon regulates antioxidant activities of crop plants under abiotic-induced oxidative stress: A review. Front. Plant Sci. 8:510.

Ismail, H., J.D. Maksimović, V. Maksimović, L. Shabala, B.D. Živanović, Y. Tian, S.E. Jacobsen, and S. Shabala. 2015. Rutin, a flavonoid with antioxidant activity, improves plant salinity tolerance by regulating $\mathrm{K}+$ retention and $\mathrm{Na}+$ exclusion from leaf mesophyll in quinoa and broad beans. Funct. Plant Biol. 43:75-86.

Larkindale, J. and B. Huang. 2004. Changes of lipid composition and saturation level in leaves and roots for heat-stressed and heatacclimated creeping bentgrass (Agrostis stolonifera). Environ. Expt. Bot. 51:57-67.

Larkindale, J. and B. Huang. 2005. Effects of abscisic acid, salicylic acid, ethylene and hydrogen peroxide in thermotolerance and recovery for creeping bentgrass. Plant Growth Regulat. 47:17-28.

Liang, D., F. Gao, Z. Ni, L. Lin, Q. Deng, Y. Tang, X. Wang, X. Luo, and H. Xia. 2018. Melatonin improves heat tolerance in kiwifruit seedlings through promoting antioxidant enzymatic activity and glutathione s-transferase transcription. Molecules 23:E584. doi:10.3390/molecules23030584.

Liang, Y., Q. Chen, Q. Liu, W. Zhang, and R. Ding. 2003. Exogenous silicon (Si) increases antioxidant enzyme activity and reduces lipid peroxidation in roots of salt-stressed barley (Hordeum vulgare L.). J. Plant Physiol. 160:1157-1164.

Liu, X. and B. Huang. 2000. Heat stress injury in relation to membrane lipid peroxidation in creeping bentgrass. Crop Sci. 40:503-510, doi: 10.2135/cropsci2000.402503x.

McCourt, P., L. Kunst, J. Browse, and C.R. Somerville. 1987. The effects of reduced amounts of lipid unsaturation on chloroplast ultrastructure and photosynthesis in a mutant of arabidopsis. Plant Physiol. 84:353-360.

Miller, G., V. Shulaev, and R. Mittler. 2008. Reactive oxygen signaling and abiotic stress. Physiol. Plant. 133:481-489.
Nakano, Y. and K. Assada. 1981. Hydrogen peroxide is scavenged by ascorbate specific POD in spinach chloroplasts. Plant Cell Physiol. 22:867-880.

Nawaz, M.A., Y. Huang, Z. Bie, W. Ahmed, R.J. Reiter, M. Niu, and S. Hameed. 2016. Melatonin: Current status and future perspectives in plant science. Front. Plant Sci. 6:1230, doi: 10.3389/fpls.2015.01230. Nishiyama, Y., D. Los, and N. Murata. 1999. PsbU, a protein associated with PSII is required for the acquisition of cellular thermotolerance in Synechococcus species PCC7002. Plant Physiol. 120:301-308.

Farahani, A.S. and S. Taghavi. 2018. Rutin promoted resistance of tomato against Xanthomonas perforans. Eur. J. Plant Pathol. 151:527.

Shi, H., D.X. Tan, R.J. Reiter, T. Ye, F. Yang, and Z. Chan. 2015. Melatonin induces class A1 heat-shock factors (HSFA1s) and their possible involvement of thermotolerance in Arabidopsis. J. Pineal Res. 58:335-342.

Singh, A., R. Gupta, and R. Pandey. 2017. Exogenous application of rutin and gallic acid regulate antioxidants and alleviate reactive oxygen generation in Oryza sativa L. Physiol. Mol. Biol. Plants 23:301-309.

Turgeon, A.J. 2004. Turfgrass management. 7th ed. Prentice Hall, Upper Saddle River, NJ.

Vigh, L., Z. Gombos, I. Horvath, and F. Joo. 1989. Saturation of membrane lipids by hydrogenation induces thermal stability in chloroplast inhibiting the heat dependent stimulation of Photosystem I mediated electron transport. Biochim. Biophys. Acta 979:361-364. Wang, M., Y. Tadmor, Q.L. Wu, C. Chin, S.A. Garrison, and J.E. Simon. 2003. Quantification of protodioscin and rutin in asparagus shoots by LC/MS and HPLC methods. J. Agr. Food Chem. 51:61326136.

Whitaker, B.D., J.D. Klein, W.S. Conway, and C.E. Sams. 1997. Influence of pre-storage heat and calcium pre-treatments on lipid metabolism in golden delicious apples. Phytochemistry 45:465-472. Xu, W., S.Y. Cai, Y. Zhang, Y. Wang, G.J. Ahammed, X.J. Xia, K. Shi, Y.H. Zhou, J.Q. Yu, R.J. Reiter, and J. Zhou. 2016. Melatonin enhances thermotolerance by promoting cellular protein protection in tomato plants. J. Pineal Res. 61:457-469.

$\mathrm{Xu}, \mathrm{Q}$. and B. Huang. 2004. Antioxidant metabolism associated with summer leaf senescence and turf quality decline for creeping bentgrass. Crop Sci. 44:553-560.

Yang, J., J. Guo, and J. Yuan. 2008. In vitro antioxidant properties of rutin. Lebensm. Wiss. Technol. 41:1060-1066.

Yang, W., X. Xu, Y. Li, Y. Wang, M. Li, Y. Wang, X. Ding, and Z. Chu. 2016. Rutin-mediated priming of plant resistance to three bacterial pathogens initiating the early sa signal pathway. PLoS One 11:e0146910.

Zhang, X. and R.E. Schmidt. 2000. Hormone-containing products' impact on antioxidant status of tall fescue and creeping bentgrass subjected to drought. Crop Sci. 40:1344-1349, doi: 10.2135/ cropsci2000.4051344x. 